\title{
Sediment transport in an active erodible channel bend of Brahmaputra river
}

\author{
TAPAS KARMAKER, Y RAMPRASAD and SUBASHISA DUTTA* \\ Department of Civil Engineering, Indian Institute of Technology Guwahati, \\ Assam 781039 \\ e-mail: subashisa@iitg.ernet.in
}

MS received 13 December 2009; revised 29 August 2010; accepted 14 September 2010

\begin{abstract}
Spatial variation of sediment transport in an alluvial sand-bed river bend needs to be understood with its influencing factors such as bank erosion, secondary current formation, land spur and bed-material characteristics. In this study, detailed hydrographic surveys with Acoustic Doppler Current Profiler (ADCP) were conducted at an active erodible river bend to measure suspended load, velocity, bathymetric profile and characteristics of the bed material. Study indicates the presence of multi-thread flow in the channel bend. Local variation of sediment transport is primarily controlled by active bank erosion, land spur and sand bar formation. Vertical distribution of suspended sediment concentration follows a power function with normalized depth. Average bed-material concentration at the reach level is computed from observed sediment profiles, and is compared against various sediment transport functions. Results show that the sediment transport function suggested by Yang gives better predictions for this reach. Transverse bed slopes at critical survey transects were computed from the bathymetric data and evaluated with analytical approaches. Out of three analytical approaches used, Odgaard's approach estimates the bed slopes fairly close to the observed one. These two functions are suitable in the Brahmaputra river for further morphological studies.
\end{abstract}

Keywords. Sediment transport; transverse bed slope; secondary current; bank erosion.

\section{Introduction}

Formation of braiding pattern is quite common in case of any wide river with gentle slope in alluvial flood plains. Even in the straight reaches, formation of the multi-thread flow can be found very often. The close interrelationship between the river flow and channel formation governs many river channel processes such as meander planform, bed topography, bank erosion and lateral migration, which in turn provide the basis for analysis and hydrodynamic

*For correspondence 
and sediment transport modelling in a curved channel (Chang 1988). Under the influence of the centrifugal acceleration, the flow in the curved channel experiences secondary current as spiral motion of the flow directed normal to the main flow and the super-elevation of the water surface. The secondary current, which develops upon entering a channel bend, will eventually reach an equilibrium condition if sufficient bend length is available. In that state the flow is called as fully developed and the river profile does not change unless there is significant change in the discharge or other influential parameters such as sediment influx.

Several researchers have contributed towards determining the equilibrium sediment profile and bed-material concentration. These studies were mainly based on laboratory experiments and limited in situ observed data at river scale. Zimmermann \& Kennedy (1978), Falcon-Ascanio \& Kennedy (1983), and Odgaard (1981) developed the bed slope function from flume studies and calibrated using the river data. Falcon-Ascanio \& Kenedy (1983) assumed that the radial component of fluid force balances the submerged weight component down the transverse bed slope and thus defined the transverse bed slope as:

$$
S_{t}=\frac{D}{R_{c}} F_{d} \frac{\sqrt{8 \tau_{*_{c}}}}{1-\lambda} \frac{1+f^{1 / 2}}{1+2 f^{1 / 2}},
$$

where $S_{t}$ is the transverse bed slope, $D$ the depth of flow, $R_{c}$ the radius of curvature, $\tau_{*_{c}}$ the critical shields stress, $\lambda$ the bed layer porosity, $f$ the friction factor and $F_{d}$ is the particle densimetric Froude number defined by:

$$
F_{d}=\frac{U}{\sqrt{\frac{\rho_{s}-\rho}{\rho} g d}},
$$

where $U$ is the depth averaged longitudinal velocity, $\rho$ the density of water and $\rho_{s}$ density of sediment, $d$ the particle median diameter $\left(d_{50}\right)$ and $g$ the gravitational acceleration.

Odgaard (1981) developed a method for computing transverse bed profile based on incipient motion of sediment. It was assumed that the size of the bed forming particles are just about to move in the longitudinal direction by rolling about their points of support. This is due to the fact that a particle starts moving only when the grain shear stress exceeds the critical shear stress $\tau_{c}$.

$$
S_{t}=\frac{3 \alpha}{2} \frac{D}{R_{c}} \frac{U^{2}}{\left((s-1) g d_{c r}\right)^{1 / 2}}\left(\frac{1+m^{\prime}}{m^{\prime}\left(2+m^{\prime}\right)}\right),
$$

where $\alpha$ the projected area-volume ratio of the particle, $s$ the specific gravity of the particle, $d_{c r}$ the diameter of particle whose motion is impending, $m^{\prime}$ the reciprocal of the velocity exponent for grain roughness.

Zimmermann \& Kennedy (1978) equated the radial component of the fluid drag force parallel to the bed with the particles submerged weight component. These are related to the stream flow by equating directly the moment of the radial boundary shear stress to the moment produced due to non-uniformity of the centrifugal force about the channel axis. The proposed final form of the transverse bed slope can be given by:

$$
S_{t}=0.5 \alpha \frac{D}{R_{c}} F_{D}^{2}\left(\frac{1+n u n}{n u n(2+n u n)}\right),
$$

where $F_{D}$ the drag force of the fluid and nun is the nunner's number, equals to the inverse of the square root of friction factor. 
Engelund \& Hansen (1967) applied Bagnold's stream power approach to derive the bedmaterial transport rate for equilibrium conditions:

$$
C_{s}=0.05\left(\frac{G}{G-1}\right) \frac{U S}{((G-1) g d)^{1 / 2}} \frac{R S}{(G-1) d},
$$

where $C_{s}$ is the sediment concentration by weight, $G$ the specific gravity of the sediment particle, $S$ the longitudinal slope, $R$ the hydraulic radius, $d$ the median particle size $(\mathrm{m})$. However, this equation is applicable to the sand bed rivers with particle size greater than $0.15 \mathrm{~mm}$ in the upper flow regime. The basic approach of Bangnold's stream power generation was also utilized by Ackers \& White (1973) and slightly differs from the above equation. In this method the bed material load concentration is related to the function of mobility number $\left(F_{g}\right)$

$$
C_{s}=c G \frac{d}{R}\left(\frac{U}{U_{*}}\right)^{n}\left(\frac{F_{g}}{A}-1\right)^{m},
$$

where $U_{*}$ is the shear velocity defined as $\sqrt{\tau / \rho}, \tau$ the shear stress developed at the river bed; $A, c, m$ and $n$ are the coefficients derived from the best fit curve of the laboratory test data for sediments greater than $0.4 \mathrm{~mm}$ and Froude number is less than 0.8 . The mobility number $\left(F_{g}\right)$ is defined by:

$$
F_{g}=\frac{\left(U_{*}\right)^{n}}{[g d(s-1)]^{1 / 2}}\left[\frac{U}{\sqrt{32} \log (10 R / d)}\right]^{1-n} .
$$

Yang (1972) developed the sediment transport equation by relating the bedload to the rate of energy dissipation of the flow as an agent for sediment transport. In case of steady uniform flow the rate of energy dissipation is due to change in potential energy without any change in kinetic energy and the rate of dissipation of potential energy per unit weight of water over a reach length is given by the product of velocity and slope $(U S)$, which is also known as unit stream power. As the sediment transport mainly occurs in the turbulent flows, hence sediment concentration is related to the unit stream power.

$$
\log C_{s}=M+N \log \left(\frac{U S}{w_{s}}\right)
$$

where $w_{s}$ the fall velocity of the sediment, $M$ and $N$ are the dimensionless parameters related to flow and sediment characteristics. These $M$ and $N$ parameters can be estimated through multiple regression analysis of laboratory data. However, the sediment fall velocity $\left(w_{s}\right)$ is also dependent on the sediment concentration $\left(C_{s}\right)$ of the flow. The transport equation for sand $\left(d_{50} \leq 2 \mathrm{~mm}\right)$ is given by Yang (1973):

$$
\begin{aligned}
\log C_{s}= & 5.435-0.286 \log \frac{w_{s} d}{v}-0.457 \log \frac{U_{*}}{w_{s}} \\
& +\left(1.799-0.409 \log \frac{w_{s} d}{v}-0.314 \log \frac{U_{*}}{w_{s}}\right) \log \left(\frac{U S}{w_{s}}-\frac{U_{c} S}{w_{s}}\right) .
\end{aligned}
$$

All the above equations are validated with the river data; still there is no stand alone equation to cover all types of river. Moreover, the complex nature of flood hydrograph during the monsoon period in a braided river critically affects the bank erosion and subsequently 


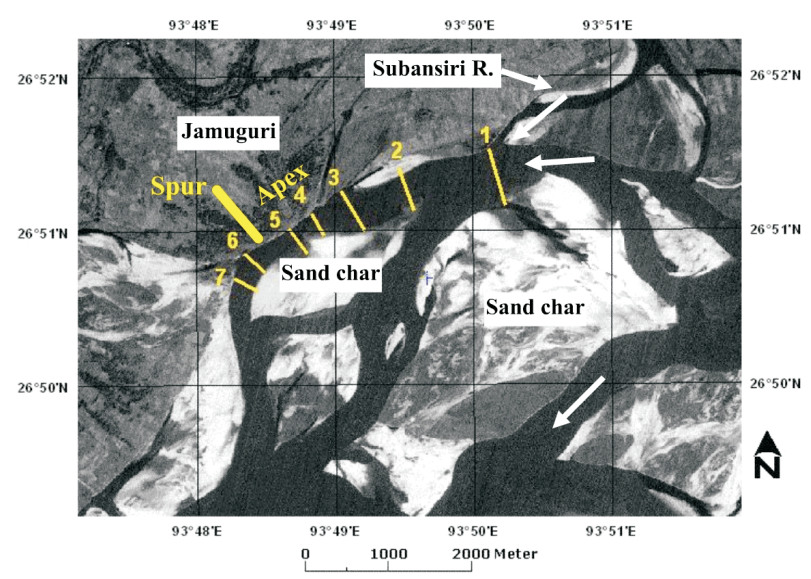

Figure 1. Index map showing the study river reach of Brahmaputra (Numerical numbers in the figure indicate the survey transects).

sediment transport (Karmaker \& Dutta 2010). Hence, before applying any of these equations in a river, validation of sediment transport equation with the observed sediment data is necessary. Besides this, spatial variation of suspended sediment transport in an erodible river bend is not reported so far. In this study, appropriate sediment transport function and transverse bed-slope prediction formula are identified by comparing predicted and observed one. Spatial variation of the suspended load is discussed with active morphological processes such as formation of bar, confluence of the rivers, bank erosion and land spur. Vertical distribution of suspended sediment concentration is also obtained.

\section{Study area}

The study area $\left(26^{\circ} 50^{\prime} 08^{\prime \prime} \mathrm{N}\right.$ and $\left.93^{\circ} 46^{\prime} 08^{\prime \prime} \mathrm{E}\right)$ is located at the upper reach of the Brahmaputra river at Jamuguri, India. River flows from east to west at this location. One thread of the river in this site formed a bend of about 4500 meter radius (figure 1 ). The average width of the active part of the thread is about 250 meter and the length of the bend portion is about $4 \mathrm{~km}$ long.

Detailed hydrographic survey was conducted twice: during the moderate flow condition and during high flood condition (water level nearly $1 \mathrm{~m}$ higher than the bank full discharge) for two years 2007 and 2008. The measured discharge during the high flow and moderate flow stages were about $4200 \mathrm{~m}^{3} / \mathrm{sec}$ and $2900 \mathrm{~m}^{3} / \mathrm{sec}$, respectively. The survey includes detailed data collection like bathymetry using GPS aided Echo-sounder, velocity profile through ADCP (Acoustic Doppler Current Profiler), river bed and bank soil samples. The measuring devices were mounted on an engine propelled vessel. The accuracy of the GPS instrument was \pm 1.5 meters. The longitudinal bed slope is very gentle and about 1 in 7000 (Sarma 2004).

\section{Methodology}

A program in $\mathrm{C}$ language has been developed to calculate the equilibrium transverse bed slope and bedload transport rates in a river bend. Major computational steps followed in this program are shown as a flow chart (figure 2). Based on the input data such as particle size 
diameter, average width of the river, longitudinal slope, porosity, the radius of curvature and for discharge, it calculates the flow area, hydraulic radius and average velocity by assuming an initial depth. Then Engelund's stage discharge predictor method is used to calculate the average velocity and flow discharge. The program iteratively adjusts the flow depth till the calculated discharge matches with the given discharge. Subsequently, it calculates the transverse bed slope and the bed-material concentration based on the equations (1) through (7).

The estimated hydraulic and bed-material characteristics were verified with the surveyed cross-sectional data obtained from the ADCP and Echo sounder surveys. The advance river survey instrument like ADCP gives the three-dimensional velocity profiles on a continuous moving boat facility. The instrument also keeps the record of the backscatter data which can be used to obtain the suspended sediment concentration in the river (Gartner 2004; Merckelbach 2006). Gartner (2004) calibrated the back scatter data obtained from the ADCP instruments (manufacturer RD instruments) at two locations with sufficient point sample data. He found that the suspended sediment concentration $(S C)$ (in $\mathrm{mg} / \mathrm{lit}$ ) is related with the relative back scatter $(R B)$ measured in decibell $(\mathrm{dB})$ as follows:

$$
S C=10^{\left(A+B^{*} R B\right)},
$$

where $A$ and $B$ are the calibration constants for the instrument. The above formula is based on the sonar equation for sound scattering from the suspended particles in the flow. The calibrations constants are determined through the method of regression of concurrent back scatter with the known mass concentration measured using a semi-log plane. The relative backscatter $(R B)$ is the sum of the echo level measured at transducer plus the two-way transmission losses (for detail, see Thevenot et al 1992).

As in the present study, same model of ADCP instrument was used. However, to verify the calibration of the instrument with the one used by Gartner (2004), few point sample data was used. Water samples were collected from the location at the various depth and analysed in the laboratory for the suspended sediment concentration. It has been found that the equation (9) holds good for the present case.

Analysis of the ADCP data has been carried out using Matlab software (ver. 7). A $3 \times 3$ median filter window has been used to eliminate the local noises in the raw ADCP data for analysing velocity and sediment concentration.

\section{Results and discussion}

Five bed soil samples and eleven bank soil samples were collected and analysed for the particle size distribution (Karmaker \& Dutta 2009). The analysis indicates the average $d_{50}$ value of the river bed material in this reach is $0.16 \mathrm{~mm}$. It has been observed that the river bank material is of fine to medium sand $\left(d_{50}=0.16 \mathrm{~mm}\right.$ to $\left.0.22 \mathrm{~mm}\right)$ type with interlaced clay soil $\left(d_{50}=0.06 \mathrm{~mm}\right)$. Ten water samples were collected from various transects at the reach and the suspended sediment concentration range was found to be $187.5-559 \mathrm{mg} / \mathrm{lit}$ (median suspended concentration is $465 \cdot 5 \mathrm{mg} / \mathrm{lit}$ ).

\subsection{Primary velocity variation}

Primary velocity plots for each transect were examined for the changes in the velocity pattern as it approaches to the active bank erosion zone. Velocities for two flow conditions as mentioned earlier were analysed. Just upstream of the transect-1, one tributary (lower branch 


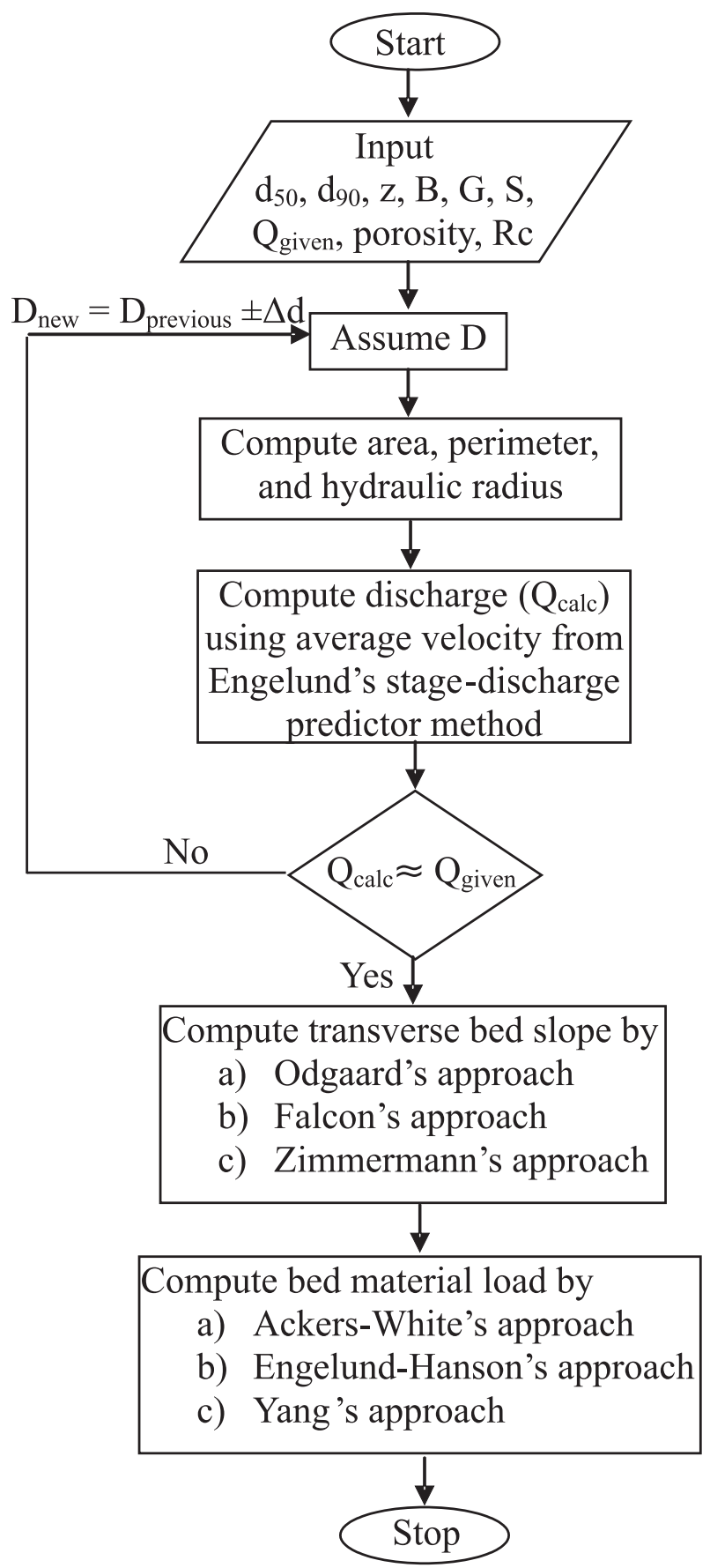

Figure 2. Flow chart for calculation of total bedload concentration and transverse bed slope.

of Subansiri river) meets to the river bend. During the moderate discharge condition two distinct flow patterns are visible (figure 3a). Relatively low velocity zones up to $70 \mathrm{~m}$ from the bank and a very high velocity zone near $80 \mathrm{~m}$. In transect-2 (figure 3b), two flows are partially mixed up, although multi-thread flow is visible. Richardson \& Thorne (2001) also found 


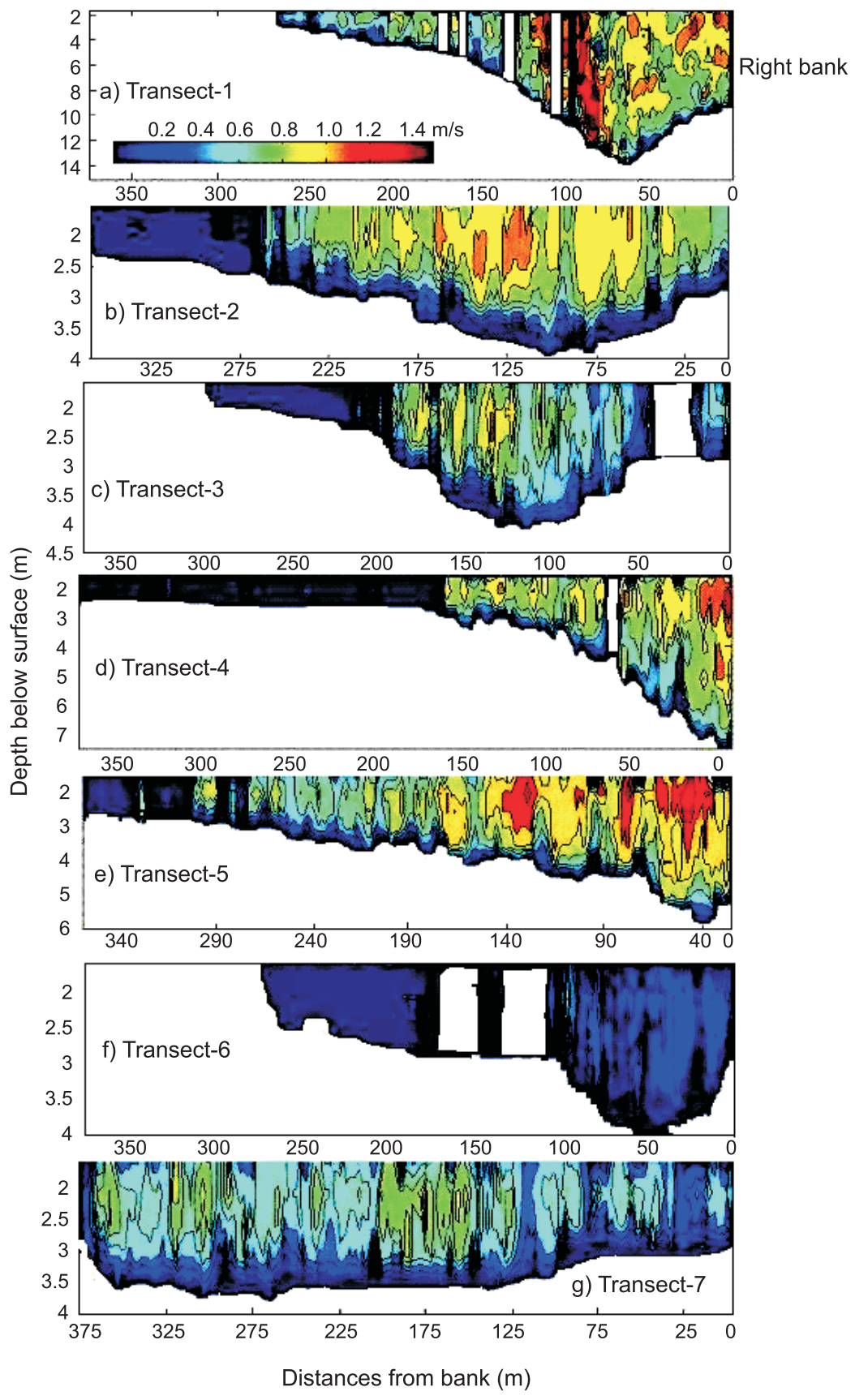

Figure 3. Primary velocity contour for the survey transects during moderate discharge condition. (a) Transect-1, (b) transect-2, (c) transect-3, (d) transect-4, (e) transect-5, (f) transect-6, (g) transect-7 (white strips in the figures are due to data recording error). 


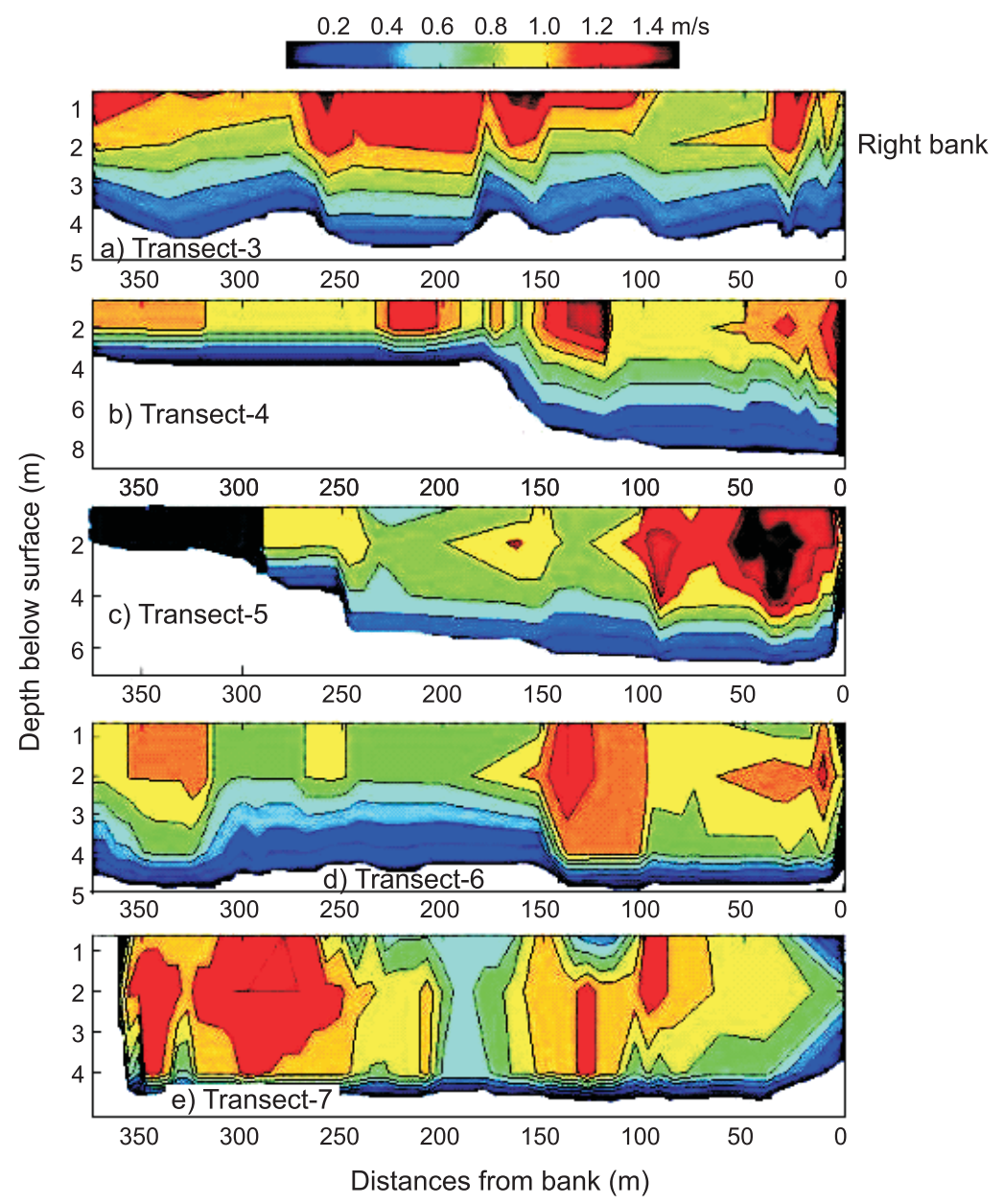

Figure 4. Primary velocity contour for the survey transects during high discharge condition. (a) Transect-3, (b) transect-4, (c) transect-5, (d) transect-6, (e) transect-7.

the presence of similar multi-thread flow in the braided river system for Brahmaputra river reach in Bangladesh. The cores of the flow-threads are at $30 \mathrm{~m}, 70 \mathrm{~m}$ and $125 \mathrm{~m}$. Due to the presence of sand bar near the bank (figure 1), the main flow has shifted towards the left bank (figure 3c). But at the apex of the bend (figure 3d), due to the centrifugal motion there is a formation of deep scour pool near the bank. The bank erosion is also active in this transect. Distinct transverse slope towards the bank ensures the presence of very high primary velocity near the bank. Similarly, in the transect-5, transverse slope is present and a very high velocity core is near the bank. However, multiple thread flow is also visible. In the next transect (figure 3f), due to the presence of land spur just upstream of the transect, the main flow has shifted towards the left side sand bar. But the low velocity zone near the bank is not exhibited in the previous transect as it is away from the existing land spur. However, little downstream of the structure, the multi-thread flow is again prominent (figure $3 \mathrm{~g}$ ). During the high flood period, velocity distribution, shown in figure 4 , shows the similar trend of moderate flow. The data for first two transects (transects 1 and 2) are absent due to instrumental data recording 

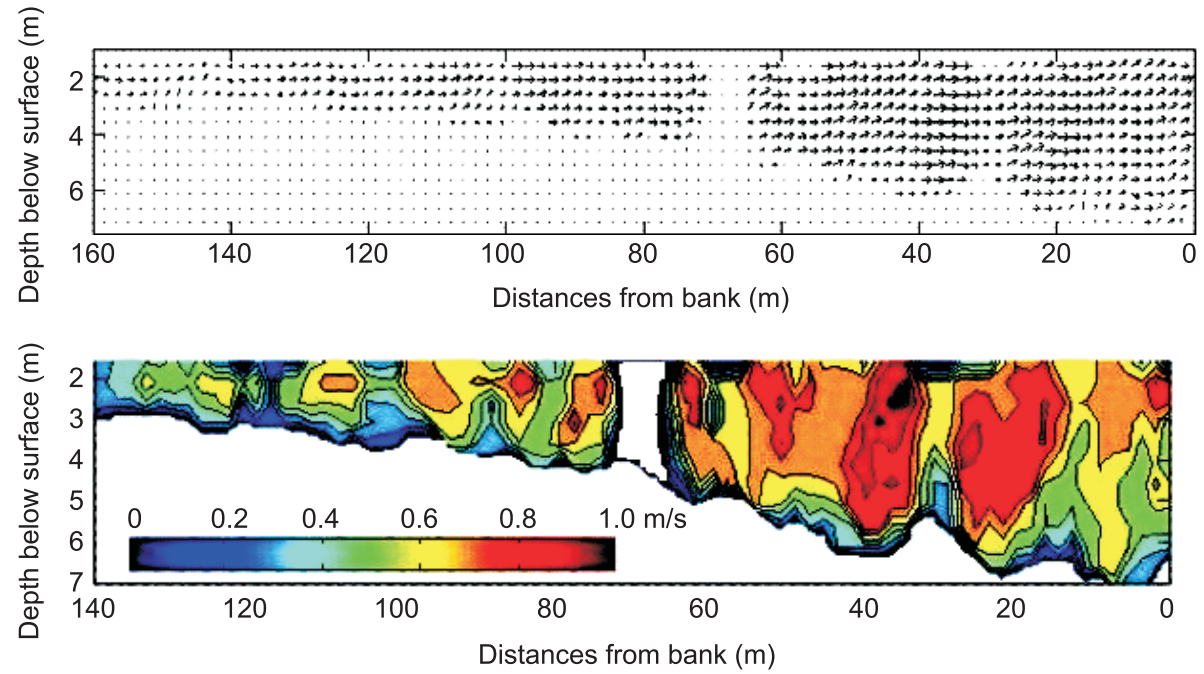

Figure 5. Secondary current at transect-4 during moderate discharge condition. (a) Vector, (b) magnitude (white strips in the figures are due to data recording error).

problem. For other transects, locations of high velocity zone fairly match with that of the moderate flow condition. In transects 4 and 5, near the apex of the bend, transverse bed slope is prominent whereas in other transects it is absent. Multi-thread flow pattern are found in all transects. However, at transect 5, two flow threads are closely spaced due to curvature effect, while they are well separated in other transects. Primary velocity at the thread core $(1.9 \mathrm{~m} / \mathrm{sec})$ was found to be significantly higher than the moderate discharge condition $(1.5 \mathrm{~m} / \mathrm{sec})$.

\subsection{Secondary current variation}

Transect- 4 in the present study are located exactly at the apex of a channel bend. Moreover, this section is also under active bank erosion. It has been found from the secondary current plot along the survey transects; that the strength of helical motion is negligible except transect- 4 . Figure 5a shows the vector plot of the secondary current, while figure $5 \mathrm{~b}$ for the velocity contour of secondary current. The circular motion of the secondary current in the river bend is found to be absent in this transect. For mildly sinuous river channels (sinuosity <1.2), secondary current is negligible, as reported by Chen \& Duan (2006). As this channel bend lies in mildly sinuous category (sinuosity $\sim 1.06$ ), the present field studies reconfirms about the secondary current. The velocity vectors indicate that the secondary current directs towards the bank and almost horizontal. Due to bathymetric unevenness at $30 \mathrm{~m}$ from the bank, two cores of secondary flow are prominent at $20 \mathrm{~m}$ and $40 \mathrm{~m}$. It can also be noted that the superelevation, which is very common in curved flow, is not evident in figure 5. As the channel radius is very large, the estimated superelevation is significantly small $(\sim 14 \mathrm{~mm})$ in comparison to depth of flow (Chang 1988). For this reason, during the survey, the channel water surface is considered as horizontal.

\subsection{Sediment transport function}

From the backscatter data of ADCP, the suspended sediment concentration has been estimated for each of the survey transects. Figures $6 \mathrm{a}-\mathrm{g}$ show the suspended sediment concentrations 


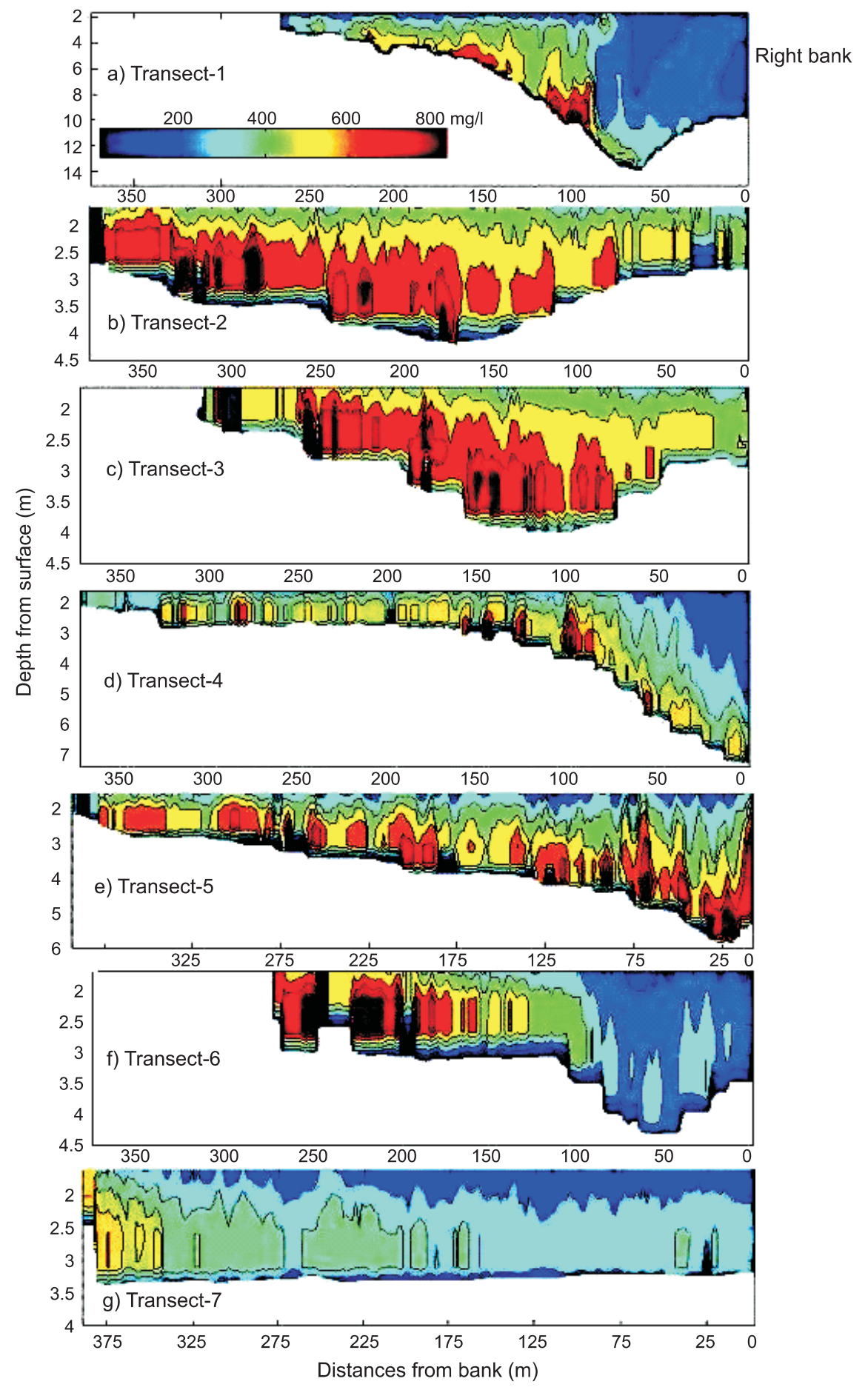

Figure 6. Suspended sediment contour for the survey transects during moderate discharge conditions. (a) Transect-1, (b) Transect-2, (c) Transect-3, (d) Transect-4, (e) Transect-5, (f) Transect-6, (g) Transect-7. 


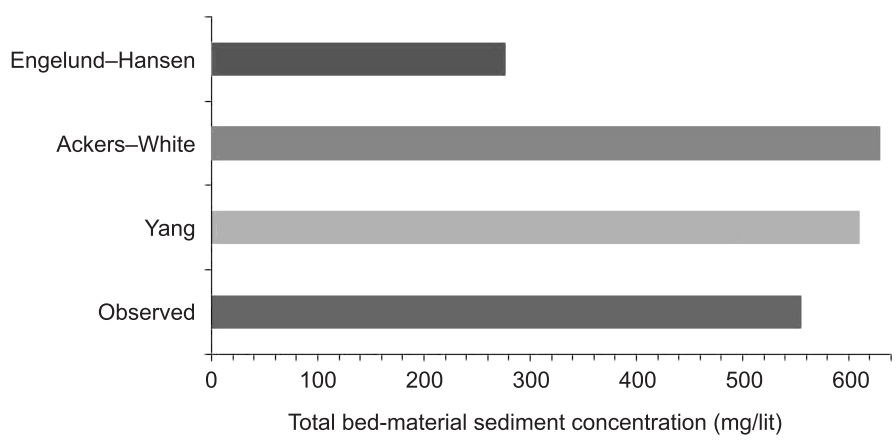

Figure 7. Comparison of the total bed-material sediment concentration functions with the observed data.

in these transects. In transect-1, as a tributary (Subansiri river) joins the main river, two separate sediment zones are visible: zone- 1 at the right hand side up to $75 \mathrm{~m}$ carries very less sediment load less than $200 \mathrm{mg} / \mathrm{lit}$. Beyond $75 \mathrm{~m}$, a zone of higher sediment load is found. In the next two transects, high sediment concentration is observed, which indicates the higher bed scouring process. Just downstream of these two transects, a bar formation resulting from the high sediment concentration has been found during the survey. Due to this, relatively less sediment concentration is found in the transect-4 (figure 6d). As this transect is under the severe bank erosion, huge sediment discharge from the bank supplied to this section. This phenomenon is reflected in the next transect-5 (figure 6e). Very high sediment concentration is observed near the bank and extended up to the top of the bank. But due to presence of the land spur at downstream of this transect, and the formation of relatively still water pool enhances the deposition of these sediment and thus less sediment concentration is observed in transect-6 (figure 6f). Further downstream, the scouring is only at the left hand side, and a relatively less sediment concentration zone is observed near the bank.

As in any transect, suspended sediment concentration varies both in the vertical and transverse direction, the median suspended sediment concentration at each transect has been considered for comparing with equilibrium sediment function equations. The estimation of total bed-material concentration using the approaches of Engelund-Hansen (1967), Ackers-White (1973) and Yang (1972) has been carried out. There is no in situ bedload measurement reported so far in case of Brahmaputra river. Goswami (1989) estimated the bedload using the bedload function developed by Laursen (1958). He found the bedload is about $15 \%$ of the total bed-material load in Bramaputra river. Considering $\pm 5 \%$ overall error in suspended sediment concentration measurement (Goswami 1989), the maximum total bed-material concentration comes about 1.25 times of the suspended sediment concentration. Based on this assumption, the concentrations were estimated using these three approaches. Figure 7 shows the comparison of the estimated suspended sediment concentration with the measured data at the river reach. Result indicates that Yang's model gives most acceptable estimation of the sediment concentration for the present river within $10 \%$ accuracy. However, the estimated suspended sediment concentration in the channel reach from the ADCP instrument $(458 \mathrm{mg} / \mathrm{lit})$ are found closed to that of ten point water samples collected.

For all the transects, vertical concentration profile has been analysed along the maximum sediment concentration plane. In transect-5, which is just downstream of the active bank 
Dimensionless sediment concentration

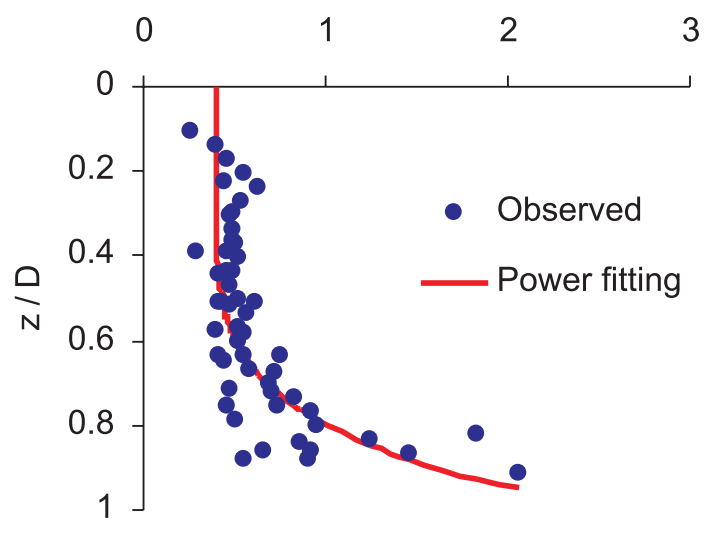

Figure 8. Normalized vertical sediment concentration profile.

erosion zone, it has been observed that sediment concentration is very high near the top surface. As mentioned earlier, this is due to the mixing of the eroded bank material with flow. Therefore, the vertical sediment profile in this transect has not been considered for the present analysis. As the depth of flow varies within a reach, the use of normalized depth for average sediment concentration will be more justified. Figure 8 shows the dimensionless suspended sediment concentration profile with normalized depth. A constant part from the observed sediment concentration has been deducted initially to fit the data. Robust fitting technique has been used for the present case to eliminate outlier data if any. Analysis shows that the channel of Brahmaputra river during high flow follows the power function of suspended sediment concentration $(C)$ given by:

$$
\frac{C}{C_{a v g}}=0 \cdot 39+2 \cdot 254\left(\frac{z}{D}\right)^{5 \cdot 82},
$$

where $C_{a v g}$ is the reach average suspended sediment concentration, $z$ the depth below water surface and $D$ the total depth of flow.

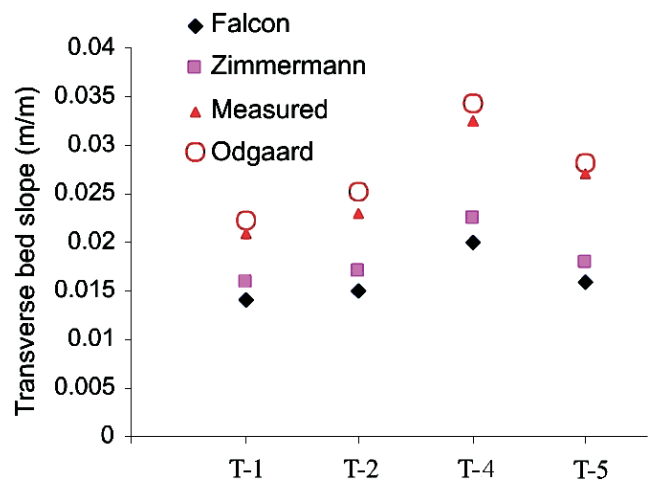

Figure 9. Comparison of the transverse bed slope functions with the observed data (T-1: transect-1; T-2: transect-2; T-4: transect-4; T-5: transect-5). 


\subsection{Transverse bed slope}

Transverse bed-slopes predicted by Falcon, Odgaard, Zimmermann approaches are compared with that of the measured cross-sections obtained from the survey. For this, four cross-sections (Transects 1, 2, 4 and 5), where the transverse bed slope is prominent, are considered. Figure 9 shows the comparison of the Falcon, Odgaard and Zimmermann approach with the observed transverse bed-slopes. Result indicates at each of the four cross-sections that Odgaard's model gives better estimation of the transverse bed slope for the study reach. The main difference in Odgaard's model to that of others approaches is that the grain roughness, was considered to compute the transverse bed slope. As the sorting process of the bed particles in a river bend takes place, it controls the distribution of grain roughness along the transverse direction.

\section{Conclusions}

The present study characterizes sediment transport and hydrodynamics of a river bend of Brahmaputra and finds the best analytical model to predict the equilibrium transverse bed slope and bed-material sediment concentration for a given discharge and longitudinal slope. Present study has also validated the predicted equilibrium transverse bed slope and the sediment concentration with the river surveyed data obtained by using advanced instruments-ADCP, GPS enabled Echo sounder, both of them record data automatically as the survey boat moves. Results show that Odgaard's approach for estimation of the transverse bed slopes for the river reach gives most acceptable result with the measured one. On the other hand, Yang's approach for estimating bedload gives acceptable range for the river reach studied here. Analysis was also carried out to obtain vertical distribution function of suspended sediment concentration in the river. Analysis of the primary velocity contours exhibits the multi-thread flow at various transects for two different discharge conditions. Study of the secondary current at the apex of the bend, indicates that a mildly sinuous river bend does not exhibit significant secondary current.

\section{References}

Ackers P, White W R 1973 Sediment transport: A new approach and analysis. J. Hydraul. Div. ASCE, 99(HY11): 2041-2060

Chang H H 1988 Fluvial processes in river engineering. (Canada: John Wiley \& Sons, Inc.) 193

Chen D, Duan J G 2006 Modelling width adjustment in meandering channels. J. Hydrol. 321: 59-76

Engelund F, Hanson E 1967 A monograph on sediment transport in alluvial streams. Teknisk Vorlag, Copenhagen, Denmark

Falcon-Ascanio M, Kennedy J F 1983 Flow in alluvial-river curves. J. Fluid Mech. ASCE, 133: 1-16

Gartner J W 2004 Estimating suspended solids concentrations from backscatter intensity measured by acoustic Doppler current profiler in San Francisco Bay, Califoria. Marine Geol. 170-187

Goswami D C 1989 Estimation of bed load transport in the Brahmaputra river, Assam. Indian J. Earth Sci. 15(1): 14-26

Karmaker T, Dutta S 2009 Predicting vulnerable bank erosion zones in a large river meander. Proc. of Water, Environment, Energy and Society (WEES)-2009, New Delhi, India, 1670-1676

Karmaker T, Dutta S 2010 Generation of synthetic seasonal hydrographs for a large river basin. J. Hydrol. 381(3-4): 287-296

Laursen E M 1958 The total sediment load of streams. J. Hydraul. Div. ASCE, 54(HY1): 1-36

Merckelbach L M 2006 A model for high-frequency acoustic Doppler current profiler backscatter from suspended sediment in strong currents. Continental Shelf Res. 1316-1335 
Odgaard A J 1981 Transverse bed slope in alluvial channel bends. J. Hydraulic Div. ASCE, 107(HY12): 1677-1694

Richardson W R, Thorne C R 2001 Multiple thread flow and channel bifurcation in a braided river: Brahmaputra-Jamuna River, Banngladesh. Geomorphology 38: 185-196

Sarma J N 2004 An overview of Brahmaputra river system. The Brahmaputra Basin Water Resources. (eds) V P Singh, N Sharma, C S P Ojha (Netherlands: Kluwer Academic Publishers) 72-87

Thevenot M M, Prickett T L, Kraus N C 1992 Tylers Beach, Virginia, dredged material plume monitoring project 27 September to 4 October 1991. Dreadging research program Technical Report DPR-92-7, US Army Corps of Engineers, Washington, DC, pp 204

Yang C T 1972 Unit stream power and sediment transport. J. Hydraul. Div. ASCE, 18(HY10): $1805-1826$

Yang C T 1973 Incipient motion and sediment transport. J. Hydraul. Div. ASCE, 99(HY10): $1679-1704$

Zimmermann C, Kennedy J F 1978 Transverse bed slopes in curved alluvial streams. J. Hydraul. Div. ASCE, 104(HY1): 33-48 